Eixo Temático: Biologia Aplicada

\title{
ET-09-010 \\ DIVERSIDADE DE FAUNA EDÁFICA EM DOIS CULTIVOS DE Manihot esculenta CRANTZ NA REGIÃO AGRESTE DE ALAGOAS
}

Alessandra da Silva ${ }^{1}$, Jéssica Maria Bezerra do Espírito Santoํㅡ, Isabelle Cristina Santos Magalhães ${ }^{2}$, Rubens Pessoa de Barros ${ }^{3}$

${ }^{1}$ Graduandas em Licenciatura em Ciências Biológicas; Universidade Estadual de Alagoas; Arapiraca-AL

${ }^{2}$ Graduanda em Licenciatura em Ciências Biológicas e Bolsista da FAPEAL; Universidade Estadual de Alagoas; Arapiraca-AL; E-mail: smagalhaes.isabelle@gmail.com.

${ }^{3}$ Professor titular do Departamento de Ciências Biológicas, da Universidade Estadual de Alagoas/Campus I. Doutorando em Proteção de Plantas no Centro de Ciências Agrárias da UFAL; E-mail: pessoa.rubens@gmail.com.

$$
\text { http://dx.doi.org/10.21472/congrebio2016.et-09-010 }
$$

\section{RESUMO}

A Manihot esculenta Crantz (Euphorbiacea), conhecida por mandioca nas regiões produtoras, é uma cultura de grande importância socioeconômica, cultivada em diversas regiões brasileiras. Este trabalho teve como objetivo analisar e comparar a fauna edáfica existente em duas áreas de culturas de Manihot esculenta Crantz. O levantamento da fauna edáfica foi realizado nos meses de setembro a novembro de 2015 em duas regiões, uma localizada no Município de Arapiraca-AL e a outra no Município de São Sebastião-AL. Em cada região foram utilizadas armadilha do tipo pitfall, colocadas em caminhamento de zigue-zague com 5 repetições por área. Após as coletas, a identificação e a separação por ordens de classificação foram realizadas em laboratório de Ecologia e Biodiversidade, da Universidade Estadual de Alagoas/Campus I. Foram identificadas 551 espécies na fauna edáfica, distribuídos em 12 ordens, sendo Anura, Araneae, Coleoptera, Diptera, Hymenoptera, Isoptera, Lepidoptera, Odonata, Orthoptera, Pulmonata, Scolopendromorpha e Squamata as mais representativas.

Palavras-chave: Classificação; Hymenoptera; Armadilhas.

\section{INTRODUÇÃO}

A Manihot esculenta Crantz (Euphorbiacea), conhecida por mandioca nas regiões produtoras, é uma cultura de grande importância socioeconômica, cultivada em diversas regiões brasileiras nas mais diversas condições edafo-climáticas. O aumento da demanda por mandioca oferece aos agricultores a oportunidade de intensificar a produção e aumentar sua renda. Mas a adoção de uma monocultura intensiva implica riscos, inclusive surtos de pragas e doenças e esgotamento dos nutrientes do solo. A cultura da mandioca se destaca como fonte de energia na alimentação humana e animal, na indústria de derivados, e, consequentemente, como geradora de emprego e renda (SILVA, 2007).

O solo é o habitat de um grande número de organismos que estão em constante interação, cujas atividades determinam, em grande parte, as propriedades físicas, químicas e biológicas do solo. A atividade da fauna edáfica contribui para a estrutura do solo por meio da movimentação de partículas minerais, orgânicas, ciclagem de nutrientes, constituindo um ambiente fértil, aumentando a porosidade do solo, através de atividades biológicas (Höfer et al., 2001). A fauna edáfica ocupa diversos tróficos dentro da cadeia alimentar no solo e afeta a produção primária de maneira direta e indireta, para a agricultura ecológica, a macrofauna do 
solo está em uma dimensão especial principalmente pela importância da matéria orgânica para os manejos dos sistemas (Morselli, 2009).

O presente trabalho teve como objetivo fazer um levantamento da fauna edáfica existente em duas áreas de culturas de Manihot esculenta Crantz na região Agreste de Alagoas, utilizando a armadilha pitfall.

\section{MATERIAIS E MÉTODOS}

A pesquisa foi realizada no período de setembro a novembro de 2015, trata-se de duas regiões do Agreste Alagoano, uma localizada no Município de Arapiraca-AL e a outra no Município de São Sebastião-AL. Para esta pesquisa foi escolhido na área de campo, pontos aleatórios e em zigue-zague a cada $5 \mathrm{~m}$ em uma área de $1000 \mathrm{~m}^{2}$, onde foram realizados três métodos de coleta de fauna edáfica, utilizando a armadilha pitfall, tanto na região A quanto na região B.

As armadilhas do tipo pitfall são utilizadas para capturar os invertebrados tanto da mesofauna, quanto da macrofauna que atuam na interface solo-serapilheira. Esse método pode dar uma indicação da atividade da fauna epígea, ou seja, dos componentes que atuam, principalmente na superfície do solo, tendo um carácter mais qualitativo que quantitativo (MOLDENKE, 1994).

Para a coleta da fauna edáfica foram utilizadas garrafas pets $(2,5 \mathrm{~L})$ cortadas ao meio, enterradas ao nível do solo contendo água na altura de $10 \mathrm{~cm}$ e adicionadas algumas gotas de detergente, para quebrar a tensão superficial. Em cada área da pesquisa, foram instaladas cinco armadilhas espaçadas a $5 \mathrm{~m}$.

No estudo do comportamento ecológico da macro e mesofauna edáfica, mensurou-se o número total de indivíduos e foram feitas comparações das regiões no período estudado, utilizando: o índice de diversidade de Shannon $(\mathrm{H}=-\Sigma$ pi. Log pi, onde pi $=$ ni $/ \mathrm{N}$; ni = densidade de cada ordem; $\mathrm{N}=\Sigma$ da densidade de todas as ordens). O índice de Shannon (H) é o índice que quantifica e compara a diversidade de espécies de uma determinada comunidade, habitat ou região. $\mathrm{O}$ índice $(\mathrm{H})$ assume valores de zero a cinco, sendo que quanto mais próximo de zero, maior é a dominância do grupo em detrimento a outro. Este índice expressa riqueza $\left(\mathrm{n}^{\circ}\right.$ espécies) e uniformidade (distribuição de indivíduos) em determinada área (BEGON et al. 1996).

\section{RESULTADOS E DISCUSSÕES}

Nas áreas com o cultivo de Manihot esculenta Crantz, a interferência contínua no uso do solo pelo homem através das práticas agrícolas, pode apresentar um desequilíbrio na diversidade da fauna edáfica. No total foram coletados 551 indivíduos agrupados em 12 ordens de seres vivos nas duas regiões de cultivo, sendo 401 espécies agrupadas em 10 ordens presentes no Município de Arapiraca-AL e 150 espécies agrupadas em 6 ordens no Município de São Sebastião-AL. As principais ordens encontradas foram Anura, Araneae, Coleoptera, Diptera, Hymenoptera, Isoptera, Lepidoptera, Odonata, Orthoptera, Pulmonata, Scolopendromorpha e Squamata.

Na região A as ordens que obtiveram maior densidade foram Hymenoptera com 0,232 ind $/ \mathrm{m}^{2}$ e Diptera com 0,62 ind $/ \mathrm{m}^{2}$, assim como na região B as ordens com maior densidade foram Hymenoptera com 0,125 ind $/ \mathrm{m}^{2}$, Orthoptera com 0,009 ind $/ \mathrm{m}^{2}$ e Coleoptera com 0,007 ind $/ \mathrm{m}^{2}$. A ordem Hymenoptera é composta pelas formigas que são comumente citadas como bioindicadores de alterações no manejo do solo, especialmente durante a reabilitação do solo (ANDERSEN et al., 2002). (Figura 1). 


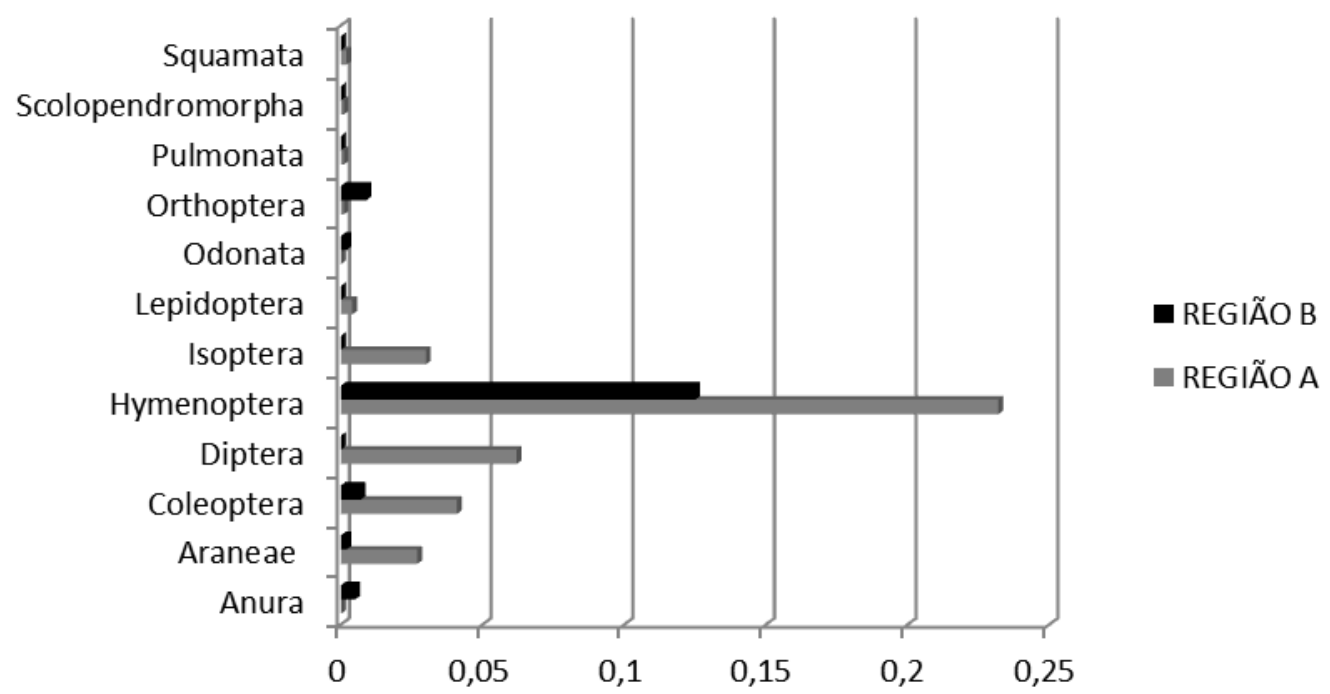

Figura 1. Densidade das ordens da macro e mesofauna edáfica encontrados no cultivo de Manihot esculenta Crantz nos Municípios de Arapiraca-AL e São Sebastião-AL.

A ordem Hymenoptera com $(\mathrm{H})$ 0,23 e a Diptera com $(\mathrm{H})$ 0,8 dominou a região A. Com valores de $(\mathrm{H})$ 0,07 a ordem Hymenoptera e (H) 1,35 a ordem Coleoptera dominou a região $B$. As segundas ordens mais representativas dentre as demais avaliadas na região A foi a Coleoptera com valores de (H) 0,98 e na região B foram Anura e Orthoptera com valores de $(\mathrm{H})$ 1,47. (Figura 2).

Analisando a variação do número de indivíduos de cada ordem da macro e mesofauna edáfica estudados, não houve diferença significativa entre as regiões, pois uma única ordem predominou nas duas regiões analisadas.

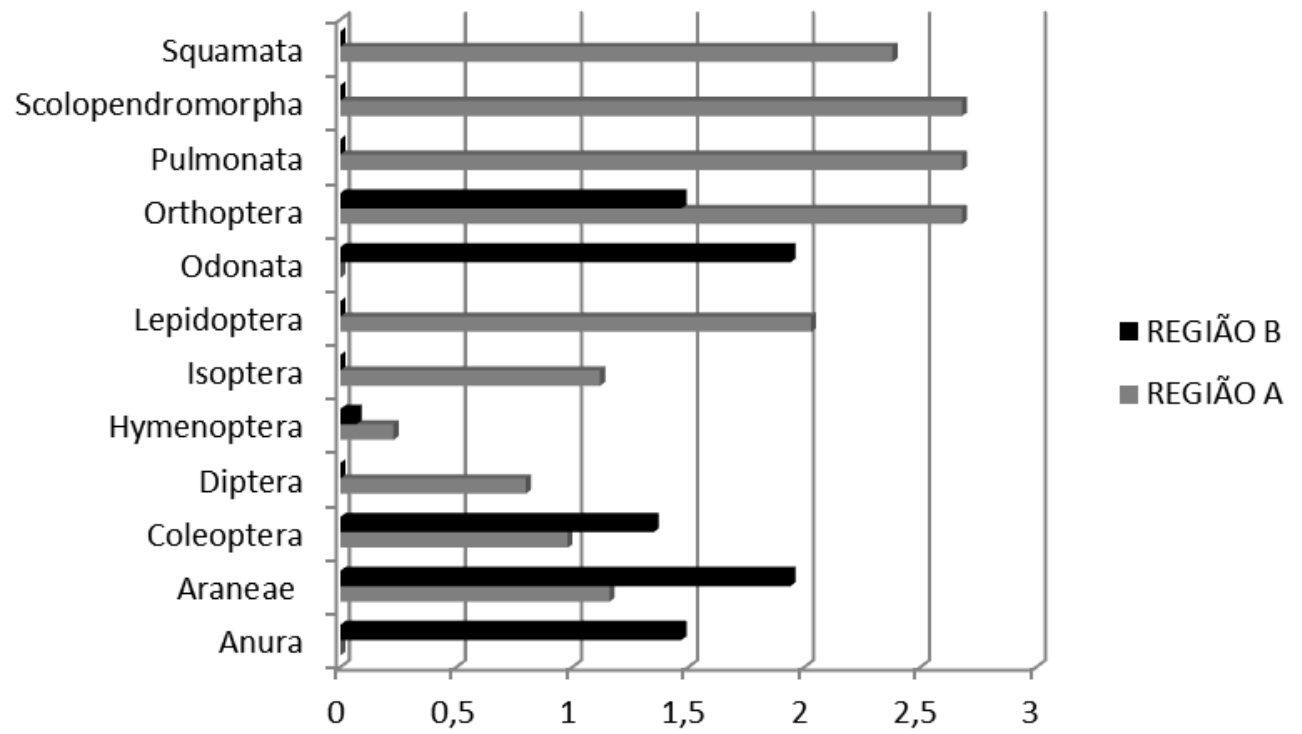

Figura 2. Índice de Shannon $(\mathrm{H})$ para as ordens da macro e mesofauna edáfica encontrados no cultivo de Manihot esculenta Crantz nos Municípios de Arapiraca-AL e São Sebastião-AL. 


\section{CONCLUSÃO}

Portanto, os levantamentos da fauna edáfica realizado tanto no município de ArapiracaAL (região A), quanto no município de São Sebastião-AL (região B) no cultivo de Manihot esculenta Crantz, apresentaram diversidades de indivíduos, porém obteve a mesma ordem representativa. O levantamento realizado foi de grande importância para o conhecimento da diversidade de indivíduos edáficos existentes nas duas regiões no agreste de Alagoas.

\section{REFERÊNCIAS}

ANDERSEN, A. N.; HOFFMANN, B. D.; MÜLLER, W. J.; GRIFFITHS, A. D. Using ants as bioindicators in land management: simplifying assessment of ant community responses. Journal of Applied Ecology, v. 39, n. 1, p. 8-17, 2002. http://dx.doi.org/10.1046/j.13652664.2002.00704.X

AQUINO, A. M. Manual para macrofauna do solo. Seropédica: Embrapa Agrobiologia, 2001. (Embrapa-CNPAB. Documentos, 130).

BEGON, M.; HARPER, J. L.; TOWNSEND, C. R. Ecology: individuals, populations and communities. 3. ed. Oxford: Blackwell Science, 1996.

BEZDICEK, D.; SMITH, S.; TABATABAI, A.; WOLLUM, A. (Ed.). Methods of soil analysis: microbiological and biochemical properties. Madison: SSSA, 1994. (Soil Science Society of America Book Series, 5).

FARIAS, A. S. C.; FERNANDES, M. E. B.; REISE A. Comparação da produção de serapilheira de dois bosques de mangue com diferentes padrões estruturais na península Bragantina, Bragança, Pará. Nat. v. 1, n. 3, 2006.

IBGE - Instituto Brasileiro de Geografia e Estatística. Manuais técnicos em geociências. Divulga os procedimentos metodológicos utilizados nos estudos e pesquisas de geociências. Rio de Janeiro. 2 ed. Rio de Janeiro: IBGE, 2007.

MOLDENKE, A. R. Arthropods. In: WEAVER, R. W.; ANGLE, S.; BOTTOMLEY, P.; MORSELLI, T. B. G. A. Biologia do Solo. Pelotas: Ed. Universitária, UFPEL/PREC, 2009.

PEREIRA, R. C.; ALBANEZ, J. M.; MAMÉDIO, I. M. P. Diversidade da meso e macrofauna edáfica em diferentes sistemas de manejo de uso do solo em Cruz das Almas-BA. Magistra, v. 24, n. especial, p. 63-76, 2012.

SILVA, R. F.; TOMAZI M.; PEZARICO C. R.; AQUINO A. M.; MERCANTE, F. M. Macrofauna invertebrada edáfica em cultivo de mandioca sob sistemas de cobertura do solo. Pesq. agropec. bras., v. 42, n. 6, p. 865-871, 2007. 